\title{
К. Аматуччи
}

\section{ЗАЩИТА КРЕДИТОРОВ И ЭФФЕКТИВНОСТЬ МЕХАНИЗМА ОТВЕТСТВЕННОСТИ УПРАВЛЯЮЩИХ В УСЛОВИЯХ КРИЗИСА НА ПРЕДПРИЯТИИ: УПУЩЕННЫЕ ВОЗМОЖНОСТИ В РАМКАХ РЕФОРМЫ РОРДОРФА*}

В статье анализируется отсутствие какой-либо пользы от последней реформы итальянского законодательства о несостоятельности, которое должно быть обязательным атрибутом правового регулирования в условиях бизнес-кризиса. Ответственность директоров несостоятельных компаний исторически имеет слабые пункты в итальянском регулировании вследствие его низкой эффективности. Напротив, другие юрисдикции ЕС (Франция, Испания) уделяют значительное внимание последствиям нарушений директоров в аспекте не только специфических форм возмещения ущерба, но и эффективности решений (дисквалификации), которые становятся последствием неправомерного поведения в будущем (Великобритания, Ирландия, Норвегия). Приоритет саморегулирования в делах о несостоятельности и отсутствие адекватного регулирования могут угрожать эффективности и целостности итальянской системы несостоятельности. Библиогр. 8 назв.

Ключевые слова: несостоятельные компании, ответственность директоров, итальянские реформы, неэффективность правоприменения, дисквалификация директоров, юрисдикции ЕС, служба несостоятельности Великобритании, саморегулирование, интегрирование рынка.

\section{Amatucci Carlo \\ PROTECTION OF CREDITORS AND DIRECTORS LIABILITY EFFECTIVENESS IN CORPORATE INSOLVENCY PROCEEDINGS. MISSED OPPORTUNITIES IN THE FRAMEWORK OF THE RORDORF REFORM}

The paper criticizes the fact that the last of several Italian insolvency law reforms exhibits an utter lack of demonstrated interest - a principle feature of any legislation that deals with the business crisis. The directors' liability of insolvent companies has historically been one of the weakest points of Italian regulation for its very low enforceability. On the contrary, other EU jurisdictions (France and Spain) pay much attention to the efficacy of directors' misconduct not only through specific forms of liabilities which make simpler the recovery of the damages caused to the company, but also through different and effective solutions (i. e., Disqualification) which impede wrongdoers from engaging in reckless behavior and wrongful conduct in future (UK, Ireland, Norway). The primacy of self-regulation in insolvency matters and the lack of adequate regulatory responses may go on to stimulate the efficiency and the integrity of Italian Insolvency system. Refs 8.

Keywords: Insolvent companies, Directors' liabilities, Italian reforms, Weak enforcement, Directors' disqualification, Other EU Jurisdictions, UK Insolvency Service, Self-dealing rules, Integrity of the market.

* Статья представляет собой переработанный (с некоторыми дополнениями) доклад на конференции на юридическом факультете Санкт-Петербургского государственного университета «Рефборма и перспективы реформы кризиса предприятия в Италии и Российской Федерации», состоявшейся 8 февраля 2016 г. в рамках соглашения о сотрудничестве между СПбГУ и Неаполитанским университетом им. Федерико II.

Аматуччи Карло - профессор коммерческого права Неаполитанского университета им. Федерико II; Италия, Неаполь, 80138, ул. Умберто I, 40; amatucci@unina.it

Amatucci Carlo - professor of University of Naples Federico II; Corso Umberto I, 40, 80138, Napoly, Italy; amatucci@unina.it

(c) Санкт-Петербургский государственный университет, 2017 


\section{1. Критические отзывы о старом итальянском законодательстве о несостоя-}

тельности (банкротстве) и закон-поручение Комиссии по реформе. Процедура признания банкротства в Италии, введенная Законом о несостоятельности (банкротстве) 1942 г. и действующая, хотя и с многочисленными изменениями, внесенными начиная с 2006 г., подвергалась критике в основном из-за длительных сроков и скромных результатов удовлетворения интересов кредиторов. Устранены ли эти недостатки в результате реформ, проведенных в период с 2005 по 2007 г.? По мнению Итальянской ассоциации котирующихся компаний и Главного управления по статистике Министерства юстиции, ответ отрицательный, несмотря на неоднократные изменения в соответствующем законодательстве. Ни сокращение сроков проведения процедуры, ни увеличение объема выплат кредиторам не были достигнуты.

Итальянские компании, состоящие в Ассоциации акционерных обществ, слишком поздно инициируют конкурсное производство, а увеличение сроков проведения этой процедуры способствует снижению стоимости компании. Основные причины следует искать:

а) в затрудненном доступе управляющего к документам, необходимым для оценки оборота средств компании (в случае непредоставления должником документов, необходимых для отчета управляющего согласно ст. 33 указанного выше Закона, выходом из ситуации могло бы стать наделение управляющего элементарными полномочиями по проведению проверки, которые вместе с тем имели бы такой же непосредственный характер, как и полномочия работников финансовых органов);

б) в спорах в рамках банкротства, которые лишь изредка решаются с помощью инструмента уступки акций и прав требования;

в) в редких случаях назначения комитета кредиторов;

г) в необходимости совершения множества действий со стороны управляющего, обязанного следовать бюрократическим процедурам и получать разрешения судьи, которые не всегда имеют значение для целей более надежной защиты интересов кредиторов;

д) в редком применении таких мер, как сдача предприятия в аренду и установление временного управления им;

е) в редких случаях продажи всего предприятия как имущественного комплекса; в основном предметом продажи выступают отдельные части имущественного комплекса;

ж) в редком применении таких мер, как передача имущественного комплекса или его части в пользование с поощрением в виде акций или долей в уставном капитале предприятия, а также перевод долга.

Из вышеизложенного следует, что в подавляющем большинстве случаев конкурсное производство завершается из-за нехватки активов, а на этапе проверки расчетов с кредиторами выплаты в пользу последних оказываются просто смехотворными.

Я не могу высказываться в отношении состоятельности таких объяснений (несмотря ни на что, они все же достойны внимания), но бесспорным остается тот факт, что в самом начале 2015 г. Министерство юстиции учредило очередную комиссию, которую возглавил председатель отдела кассаций Ренато Рордорф. Перед 
комиссией была поставлена задача провести анализ нормативной базы, накопившейся за эти годы, с целью мониторинга результатов оценки необходимости дальнейшего реформирования. В Комиссию вошли более 26 представителей судебных ведомств, адвокатуры, академических кругов и экономистов. Параллельно к работе был привлечен научный комитет из 8 членов (напоминаю, что Закон о несостоятельности (банкротстве) 1942 г. был разработан всего лишь пятью членами комитета по Торговому кодексу, а именно: профессорами Альберто Аскуини, Сальваторе Сатта, Альфредо де Марсико (последний - в области уголовной ответственности), а также магистратами Гаэтано Мирауло и Джакомо Руссо).

Министерским декретом Комиссии Рордорфа были даны поручения, связанные с длительностью и итогами конкурсных производств. Результатом работы над этими вопросами стала окончательная доработка закона-поручения, который был представлен правительству в конце 2015 г. Наиболее важными задачами, сформулированными в нем, были:

1) внедрение внутригосударственной системы регулирования в области банкротства группы компаний;

2) внедрение мер, которые могут способствовать выявлению кризиса.

Второй пункт тесно связан с перспективой более эффективного удовлетворения интересов кредиторов, учитывая большое значение заморозки оттока благосостояния, который происходит при нарушении бесперебойной оперативной деятельности компании, а также при тенденции управляющих к оппортунизму. Последние, полагая, что им нечего терять в условиях вероятного кризиса, поддаются искушению и совершают операции, сопряженные с высоким риском. Такие операции в случае положительного исхода принесут прибыль, а в случае провала приведут к еще бо́льшим убыткам, которые понесут лишь кредиторы $\left[1\right.$, p. 836 ${ }^{1}$. Чем больше снижается стоимость чистых активов, тем больше управляющие склонны к недальновидному, менее консервативному распоряжению имуществом, что создает внешний эффект благополучия. В связи с этим управляющие обязаны проявлять активность, чтобы своевременно и эффективно урегулировать кризисные ситуации, а также принять меры к защите деятельности компании в частности и стоимости ее активов в целом, контролируя совместимость административной политики с перспективами бесперебойной оперативной деятельности [3, p. 306]. Весьма распространен запрет на ведение предпринимательской деятельности, если это происходит в ущерб или с риском ущерба для третьих лиц, с учетом того, что бизнес, у которого отсутствует перспектива бесперебойной деятельности, непременно причинит ущерб кредиторам [1, р.834]. Иными словами, юридически значимая оценка инструментов ускорения, которые нацелены на своевременное выявление кризисных ситуаций и побуждают управляющих вовремя занять более консервативную позицию, входит в число основных задач любого эффективного законодательства и одновременно является одним из самых сложных уровней оценки при сравнении законодательств разных стран.

С этой целью Комиссия Рордорфа ввела меры по предупреждению и поддержке урегулирования кризиса, имеющие внесудебный и конфиденциальный характер и направленные на стимулирование заблаговременного выявления кризиса и содействие переговорам между должником и кредиторами.

\footnotetext{
${ }^{1}$ См. также более позднее существенное дополнение: [2, p. 11].
} 
Все же, несмотря на возможность использования введенного механизма, остаются сомнения в том, что Комиссия учла объективные данные, имеющиеся в наличии благодаря французской правовой системе, которая входит в число наиболее сходных с итальянской: практика введения предупредительных мер в этой стране не показала хороших результатов. Опыт французской системы действительно подтвердил, что наиболее благоприятные условия для предприятий, работников и арбитражных судов создает процедура финансового «оздоровления», введенная Законом от 26 июля 2005 г. № 2005-845.

Таким образом, нам не остается ничего иного, кроме как пожелать, чтобы предупредительные меры в Италии постигла иная участь. Сам факт того, что их доверили специализированным отделам органов урегулирования кризиса ${ }^{2}$ (даже если отвлечься от французского опыта), не вызывает ничего, кроме недоумения.

Учитывая вышеизложенное, можно утверждать, что если бы Комиссии Рордорфа не удалось выйти за рамки вопросов, заботливо подготовленных министерскими чиновниками, была бы утрачена еще одна возможность дать ответы на неизменно спорные вопросы. Решение таких вопросов могло бы содействовать тому, чтобы бремя расходов в связи с банкротством легло на реальных выгодоприобретателей от основной деятельности предприятия, слишком часто злоупотребляющих ограниченной ответственностью, которую так щедро предоставляет итальянский законодатель в последние десятилетия, не продумав возможные механизмы сдержек и противовесов.

Итак, выше мы говорили:

1) о распространении имущественной ответственности на случаи злоупотреблений со стороны владельцев предприятий (эта мера направлена в том числе на содействие пресечению деятельности организованной преступности);

2) о преодолении трудностей, возникающих при банкротстве хозяйственного общества, являющегося участником фактически несостоятельного общества при отсутствии соответствующего решения общего собрания;

3) о стимулирующих выплатах, которые побудили бы управляющих вовремя выявлять кризисные ситуации и в то же время повышали бы эффективность сдерживания в условиях малой продуктивности частного контроля (private enforcement), т. е. действий процедурных органов, которые приносят все меньше пользы при банкротстве.

Последний факт является, пожалуй, общим для всех правовых систем с незначительными отличиями, что показывает исследование «Обязанности и ответственность управляющих» («Directors' duties and liabilities»), проведенное Лондонской школой экономики (ЛШЭ; London School of Economics, LSE) в 2013 г., согласно которому «частный контроль едва ли выступает в роли значимого сдерживающего фактора при потенциальном нарушении управляющими своих обязанностей» («private enforcement is unlikely to act as a meaningful deterrent against breaches of directors' duties» $[4, \mathrm{p} . \mathrm{XVII}])$.

Теперь нам стоит задаться вопросом: по какой причине Комиссия Рордорфа не рассмотрела возможность применения превентивных мер и введения имуществен-

2 Эти отделы были созданы по Закону от 27 января 2012 г. № 3, который, в частности, требует наличия у их членов необходимого уровня технической компетентности, опыта и независимого статуса (в том числе в случае конфликта интересов), а также соблюдения ими конфиденциальности. 
ной, а не компенсаторной ответственности управляющих, как это принято в других значимых европейских правовых системах? Вновь обратимся к французскому Закону № 2005-845 о процедуре оздоровления предприятий, находящихся в кризисной ситуации, ст. 1471 которого гласит: «В случае если при ликвидации предприятия в судебном порядке будет выявлена нехватка активов, судья, если одной из причин такой нехватки стало неэффективное управление, может постановить, что бремя их восполнения частично или полностью ложится на формальных или фактических управляющих. Неэффективное управление должно сказаться на нехватке активов, но оно не обязательно является единственной причиной убытков (принцип, прямо противоположный тому, который был установлен Объединенной коллегией Кассационного суда Италии решением от 6 июня 2015 г. № 9100).

Кроме того, следует сказать и об ответственности управляющих в испанском законодательстве, которая, в случае нарушения обязанности ускорить объявление о несостоятельности, предполагает более высокую меру, т. е. возложение на управляющих ответственности по несению расходов, связанных с процессом о несостоятельности. Достойно внимания и так называемое неправомерное ведение дел (wrongful trading), существующее в английском праве; данное понятие основано не на фактической несостоятельности, а на ее возможном наступлении. Это ответственность, которую несут администраторы в случае, если в процессе конкурсного производства станет известно, что они знали или должны были знать об отсутствии у общества разумного способа избежать конкурсного производства, но тем не менее не предприняли никаких мер по минимизации убытков кредиторов.

2. Ответственность управляющих и превентивная эффективность норм о дисквалификации руководителей в правовых системах некоторых европейских стран. Оставаясь в рамках темы юридических инструментов, назначение которых - побудить управляющих общества заблаговременно принять консервативный курс во избежание еще большего материального ущерба, и учитывая длительные сроки и низкие результаты действий органов, уполномоченных в области банкротства, по привлечению к ответственности управляющих и бухгалтеровревизоров, которые часто являются владельцами имущества, совершенно несоразмерного значительным компенсационным выплатам (скромные максимальные размеры выплат по страховым полисам мало влияют на ситуацию), необходимо ответить на вопрос, почему Комиссия Рордорфа даже не огляделась и, следуя примеру прочих европейских правовых систем, не рассмотрела возможность закрепления в законе-поручении института, который был бы основан на так называемой дисквалификации управляющих.

Институт дисквалификации, присутствующий в некоторых правовых системах, в том числе в Норвегии, Великобритании, Германии, Ирландии, Финляндии, Дании и Швеции, предусматривает наложение санкций (наряду с последующим смещением с должности управляющего, т.е. со значительным отдалением ответственного лица от рынка) за халатные действия тех, кто привел предприятие к несостоятельности или усугубил ее (в том числе путем ведения деятельности такого лишенного перспектив предприятия), что возложило на кредиторов расходы, связанные с процессом о несостоятельности. Аналогичные санкции предусмотрены и в итальянском законодательстве, но лишь факультативно к уголовной ответственности, полагающейся за совершение некоторых преступлений, которые, конечно, 
не встречаются ни при каком сценарии недобросовестного ведения деятельности управляющими.

Распространенным ratio дисквалификации в вышеупомянутых правовых системах является защита общих интересов - «целостности предпринимательской среды» (the integrity of the business environment), как говорят англичане, - посредством удаления с рынка недобросовестных управляющих, которые злоупотребили привилегией ограниченной ответственности. В некоторых правовых системах (например, британской) судебная власть может запретить управляющим параллельное участие в управлении другими обществами на срок от трех (см. изменения от 2015 г.) до пятнадцати лет. Вместо того чтобы двигаться по ранее означенным ориентирам, которые предполагают имущественную или компенсаторную ответственность управляющих несостоятельных обществ, совершающих незаконные действия, дисквалификация нацелена на защиту интересов кредиторов с помощью сдерживающего инструмента удаления с рынка ответственных субъектов.

Впервые этот институт (его введение в настоящий момент рассматривается и канадским законодателем) появился в правовой системе Норвегии в 1984 г. Два года спустя он был введен в Соединенном Королевстве Актом о дисквалификации руководителей компании (Company Directors Disqualification Act), который был дополнен множеством положений от 26 марта 2015 г., приведенных в Акте о малом бизнесе, предпринимательстве и трудовых отношениях (Small Business, Enterprise and Employment Act). Его целью было установление санкций за действия, которые были признаны в том числе повлекшими существенный ущерб благу ограниченной ответственности, как вытекает из Доклада Комиссии Корка (которая составляла CDDA - Company Directors Disqualification Act). Данные нормы законодательства были приняты в том числе как следствие трудностей с оптимизацией института так называемого неправомерного ведения дел (все еще действующего), задуманного для применения санкций в виде личной ответственности управляющих, которые придерживались недопустимой линии поведения, нанесшей существенный ущерб благу ограниченной ответственности. Действительно, английский опыт «неправомерного ведения дел» и его перспективы в области ответственности управляющих не помешали последним неоднократно совершать незаконные действия в других обществах ${ }^{3}$.

Выражая озабоченность феноменом управляющих, которые, несмотря на доведение обществ до упадка и неудовлетворение интересов кредиторов, нередко утрачивая право собственности, продолжают руководить другими предприятиями (Доклад ревизионной комиссии о Законе о несостоятельности и практике его применения; Report of the Review Committee on Insolvency Law and Practice), Комиссия Корка сочла институт функциональным в плане некоторого нравственного воздействия на рынок и подчеркнула его функцию сдерживания. Не случайно по прошествии многих лет упомянутый доклад стоит в одном ряду с передовыми ис-

${ }^{3}$ Напоминаю, что регулирование в области «неправомерного ведения дел» основывается не на актуальной несостоятельности, а лишь на вероятном ее наступлении. Управляющие признаются ответственными, если в ходе конкурсного производства станет известно, что они знали или должны были знать об отсутствии у общества разумного способа избежать конкурсного производства, но тем не менее не предприняли никаких мер по минимизации убытков кредиторов. 
следованиями нормативных техник, способных повлиять на поведение субъектов, занимающих высшие должности в обществах [5].

В целях более четкого понимания того, что явилось основой (humus) введения дисквалификации в Соединенном Королевстве (напомним, первый закон о банкротстве в этой стране был принят в 1542 г.), а в более общем смысле - способа прочесть и истолковать предпринимательское право и законодательство о банкротстве, полезно привести известное судебное правило, согласно которому общественные интересы имеют право на защиту не только от деятельности тех, кто несет ответственность за наиболее распространенные нарушения деловой нравственности, но и от тех, кто через определенную управленческую позицию не показал, что ценит и соблюдает обязанности, связанные с привилегией защиты ограниченной ответственности предприятий ${ }^{4}$.

3. Функционирование норм о дисквалификации управляющих и Службе по делам о несостоятельности (Insolvency Service) в Соединенном Королевстве. В британской правовой системе действиями, предполагающими введение запретительных мер, предусмотренных Актом о дисквалификации руководителей компании, считаются также:

а) нарушение норм в области продвижения, формирования, управления и ликвидации общества (присвоение товарно-материальных ценностей, пропуск мероприятий рекламного характера, исправного ведения бухгалтерской отчетности, непредставление декларации о доходах, уклонение от сотрудничества с органами, отвечающими за процедуру);

б) нарушение антимонопольного и налогового законодательства.

Запретительные административные санкции накладываются судом по ходатайству Службы по делам о несостоятельности - административного агентства (в которой занято около 1900 служащих). Служба учреждена при Министерстве предпринимательства и инноваций 25 лет назад для исполнения по большей части инвазивных функций относительно конкурсного производства и обладает значительными полномочиями, а также выполняет совершенно неизвестную итальянской традиции в области конкурсного права надзорную функцию, осуществляемую наравне с судебной властью и контролирующую правильное и эффективное проведение конкурсных процедур.

Служба по делам о несостоятельности вправе:

а) управлять процедурами обязательной ликвидации и процедурами признания несостоятельности, а также вести по ним расследование, особенно в отношении поведения органов управления общества;

б) вести расследование управления обществом in bonis;

в) инициировать процедуры отстранения управляющих от должностей и вести Государственный реестр отстраненных управляющих;

г) действовать в качестве куратора или ликвидатора;

${ }^{4}$ О действии этого правила см. дело Re Sevenoaks Stationers (Retail) Ltd, Re Court of Appeal (Civil Division, 31 July 1990), когда управляющий обществом был признан «не соответствующим функиии руководства обществом исходя из того, что не только бесчестность, но и явная некомпетентность либо халатность являются достаточными основаниями для отстранения его от управления обществом» (http://swarb.co.uk/in-re-sevenoaks-stationers-retail-ltd-ca-1990 (дата обращения: 30.10 .2016$)$ ). 
д) действовать в качестве исполнителя и контролера в соглашениях о реструктуризации.

В случае если общество допущено к процедуре признания несостоятельности, орган, уполномоченный на ведение этой процедуры, должен подать Государственному секретарю отчет о деятельности управляющих, состоявших в этой должности в последние три года деятельности общества. Служба по делам о несостоятельности дает оценку необходимости инициирования процедуры дисквалификации. Суд призван установить сам факт того, свидетельствует ли деятельность субъекта, выполняющего административные функции, о его непригодности для целей управления другими обществами. Раздел 8 Акта о дисквалификации руководителей компании устанавливает, что суд «вводит запретительные меры, если вследствие своей деятельности юридический или фактический управляющий будет признан непригодным (unfit) для управления обществом» ввиду нарушения установленных запретов. Отстраненный управляющий не может быть управляющим общества либо прямо или косвенно участвовать в продвижении и формировании общества. Эта мера не включает в себя возможные взыскания в ходе процедуры, а также, естественно, потенциальную уголовную ответственность. Нарушение запретительных мер является преступлением и налагает на нарушителя личную ответственность по обязательствам общества. Те же последствия наступают для любого лица, действующего от имени отстраненного управляющего.

4. Доводы к размышлению о взаимосвязи «приватизации» и «целостности» в итальянском конкурсном производстве. Думаю, что такие административные санкции, как дисквалификация и деятельность государственных агентств в области конкурсных процедур, должны навести на размышления и вопросы (здесь я имею в виду итальянского толкователя) о том, почему они остаются настолько чуждыми традиции конкурсного права и почему, напротив, эти институты прочно укоренились в таких правовых системах 5 , у которых, как считают, мы позаимствовали (лишь) тенденцию к приватизации в управлении кризисом предприятия.

Очевидно, что в процессе переноса традиций конкурсного права от нас ускользнуло нечто важное: приватизация (а значит, и эффективность) и целостность системы конкурсного производства должны идти параллельно друг с другом. Тенденция к «приватизации» все более важных элементов итальянского конкурсного права, которую Альберто Йорио определил как «освоение частноправового аспекта институтов конкурсного права» [6, р.697] и которая в большей степени касается согласованных решений в области кризиса предприятия, достигаемых путем переговоров, нежели банкротства, не кажется мне удостоившейся глубокого осмысления (за редкими исключениями) относительно объема самих изменений. Среди немногих исследований отмечу глубокие и выразительные рассуждения Гуидо Росси, который в «превосходстве предприятия и в кризисе правосудия» выявил «идеологию, которой давали разные определения - от принципа невмешательства “позвольте делать” (фp. laissez-faire) до неолиберализма, - но которая в любом случае постепенно стала считать наиболее эффективной замену императивной юридиче-

${ }^{5}$ В американской системе конкурсного производства существует еще один публичный субъект - управитель (trustee) от Министерства юстиции, чья задача состоит в содействии целостности и эффективности системы конкурсного производства на благо дебиторов, кредиторов и общественных интересов. 
ской нормы, введенной в том числе для ограничения и защиты третьих лиц, частной автономией, т. е. договором между сторонами» [7, p. 146-147].

Создается впечатление, что на длинной волне коммерческой самостоятельности, неизбежная «сила тяжести» которой давно уже давит (и продолжает давить) на хозяйственное право западных стран, а теперь и всего европейского континента (как подтверждают последние сообщения европейских учреждений в сфере оздоровления предприятий, находящихся в кризисной ситуации), имеет место своего рода слепое принятие толкования, разумно оправданное невозможностью отменить ни введенные изменения, ни политическую идеологию, которая их поддерживает.

В заключение хотел бы отметить, что описанная выше ситуация имеет нечто общее с процессом трансплантации в итальянский Закон о банкротстве правил и институтов, заимствованных из правовых систем, которые считаются образцовыми в области утверждения и защиты принципов экономического либерализма и, таким образом, законодательств, для которых характерна широкая коммерческая самостоятельность в регулировании предприятия и его кризиса.

Выражаю сомнения в последовательности и состоятельности процесса введения в урегулирование кризиса на предприятии в рамках превентивных инструментов оздоровления таких высоких доз коммерческой самостоятельности, не сопряженных с системой сдержек, контрмер и инструментов корректирования и санкций, которые в исходных системах выполняют роль уравновешивания, эффективного противовеса (во избежание наступления отмеченных в итальянских судах тяжких, деформирующих последствий для находящейся в кризисе экономики). С одной стороны, я намекаю на частое злоупотребление коммерческой самостоятельностью [8, p.331], а с другой - на бесполезную и дорогостоящую деятельность по оформлению эфемерных и зачастую безосновательных договорных предложений (нередко сопровождающихся утомительными судебными спорами), которые, несомненно, способствовали разрушению благосостояния и в редчайших случаях приводили к эффективному оздоровлению и реорганизации предприятий, находящихся в кризисной ситуации.

Критика последовательности и состоятельности процесса оценки предпринимательской автономии в итальянской правовой системе основана именно на выявлении центральной роли, которую играют дисквалификация руководителей и государственные агентства в правовых системах, из которых итальянский законодатель, по его утверждению, черпал вдохновение, и которая не была учтена ни в одной реформе (включая последний закон-поручение), оставляя перекос в системе, имеющей отчетливый частноправовой характер, не уравновешенный какимлибо инструментом, корректирующим допускаемые им нарушения и неизбежные злоупотребления.

\section{References}

1. Mazzoni A. La Responsabilità gestoria per scorretto esercizio dell'impresa priva della prospettiva di continuità aziendale [Management responsibility for misuse of company operations without the prospect of continuity in governance in company law]. Amministrazione e controllo nel diritto delle società. Liber Amicorum Antonio Piras. Giappichelli [Administration and control in the company law. Liber Amicorum Antonio Piras]. Torino, 2010. (In Italian) 
2. Brizzi F. Doveri degli amministratori e tutela dei creditori nel diritto societario della crisi [Duties of Directors and creditor protection in company law]. Giappichelli. Torino, 2014, vol. I. (In Italian)

3. Sacchi R. La responsabilità gestionale nella crisi dellimpresa societaria [The management responsibility in the crisis of companies]. Giurisprudenza commerciale [Commercial Law]. 2014, vol. I. (In Italian)

4. Directors' duties and liabilities. London, School of Economics, 2013.

5. Hodges Ch. Law and Corporate Behaviour. Oxford, Hart Publishing, 2015.

6. Jorio A. La riforma fallimentare: pregi e difetti delle nuove regole [Bankruptcy reform: pros and cons of the new rules]. Giurisprudenza commerciale [Commercial Law]. 2013, vol. I. (In Italian)

7. Rossi G. I diritti dei cittadini fra le crisi dell'impresa e della giustizia [Citizens' rights among the company's crisis and justice]. Rivista delle società [Social Review]. 2014, vol. I. (In Italian)

8. Rossi A. Le proposte "indecenti" nel concordato preventivo [The "indecent" proposal in the rescue procedures]. Giurisprudenza commerciale [Commercial Law]. 2015, vol. I. (In Italian)

Для цитирования: Аматуччи К. Защита кредиторов и эффективность механизма ответственности управляющих в условиях кризиса на предприятии: возможности, упущенные в рамках реформы Рордорфа // Вестник СПбГУ. Право. 2017. Т. 8. Вып. 2. С. 173-182. DOI: 10.21638/11701/spbu14.2017.204.

For citation: Amatucci C. Protection of creditors and directors liability effectiveness in corporate insolvency proceedings. Missed opportunities in the framework of the Rordorf reform. Vestnik SPbSU. Law, 2017, vol. 8, issue 2, pp. 173-182. DOI: 10.21638/11701/spbu14.2017.204.

Статья поступила в редакцию 14 октября 2016 г. Статья рекомендована в печать 28 февраля 2017 г. 